Int. J. Odontostomat., 11(1):107-112, 2017.

\title{
Sucrose Induced Dentin Demineralization in a Microcosm Biofilm Model
}

\author{
Desmineralización de la Dentina Inducida por \\ Sacarosa en un Modelo de Biofilm Microcosmo
}

\begin{abstract}
Ana Clarissa Cavalcante Elvas Bohn'; Glauber Campos Vale'; Gislane Cristina Padovani2; Lidiany Karla Azevedo Rodrigues ${ }^{2} \&$ Raimundo Rosendo Prado-Júnior ${ }^{1}$
\end{abstract}

BOHN, A. C. C. E.; VALE, G. C.; PADOVANI, G. C.; RODRIGUES, L. K. A.; PRADO-JÚNIOR, R. R. Sucrose induced dentin demineralization in a microcosm biofilm model. Int. J. Odontostomat., 11(1):107-112, 2017.

ABSTRACT: The aim of this in vitro study was to assess the root dentin demineralization caused by a microcosm biofilm model that has been exposed to sucrose in different ways. Materials and Methods: Saliva of two volunteers was inoculated into an artificial medium for biofilm growth and dentin blocks were immersed into these media. Dentin specimens were randomly exposed to one of the five experimental conditions: $\mathrm{C}$ (control group - no saliva inoculum or sucrose), 0S (saliva inoculum without sucrose, negative control), 3S (three daily one-minute immersions in $20 \%$ sucrose), 6 S (six daily one-minute immersions in $20 \%$ sucrose), and CS (continuously immersed in $5 \%$ sucrose). After five days, biofilm was collected to determine the concentration of intracellular and extracellular polysaccharides and the dentin surface hardness loss (SHL) was measured. The experiment was carried out in triplicate. Results: The dentin SHL was higher in groups that were exposed to sucrose (3S, $6 S$ and CS) and there was a statistically significant difference between all groups ( $p<0.001)$. CS had higher concentrations of polysaccharides $(p>0.001)$ and there was no statistically significant difference between the other groups (0S, 3S and $6 S)(p>0.005)$. Conclusion: The microcosm biofilm model developed has the potential to produce root dentin demineralization at different exposures to sucrose.

KEY WORDS: biofilm, dentin, sucrose polysaccharides.

\section{INTRODUCTION}

The ability to produce caries-like lesions in vitro is useful for studying the interactions between biofilm, dental tissues and the oral environment, variables that modify the development of dental caries (Shu et al., 2000). Using a culture plate with suspended substrate model and using saliva as the inoculum can provide new insights into the properties and dynamics of the ecosystem of dental plaque (Guggenheim et al., 2001; Cheng et al., 2011; Silva et al., 2012). In vitro models are also economically and ethically important (Cheng et al.).

It is a challenge to mimic biofilm in vitro due to its complex and populous community of oral bacteria (Filoche et al., 2007). Different biofilm models display a practical and ethical way of exploring new opportunities to investigate and fight dental caries
(Salli \& Ouwehand, 2015). The most frequently used biofilm models are: the single species (Steiner-Oliveira et al., 2011), the multi-species consortia (Shu et al.; Yang et al., 2011) and the microcosm (Filoche et al., 2007; Azevedo et al., 2011). The microcosm is a laboratory system derived from natural ecosystems, where over 700 species of bacteria coexist. Its objective is to simulate the prevailing conditions of the oral environment in a study environment (Aas et al., 2005).

Sucrose has been extensively used in in vitro studies as a source of nutrients for microorganisms. It is the carbohydrate that is most consumed by the world population and the most cariogenic (Aires et al., 2008). The presence of this carbohydrate reduces $\mathrm{pH}$, and promotes structural changes in biofilm

\footnotetext{
${ }^{1}$ Restorative Dentistry Department, Federal University of Piauí, Campus Universitário Ministro Petrônio Portella, Teresina (PI), Brazil. ${ }^{2}$ Department of Operative Dentistry, Faculty of Pharmacy Dentistry and Nursing, Federal University of Ceará, Fortaleza (CE), Brazil.
} 
(high porosity) (Cury et al., 2000) that facilitate the diffusion of acids and sugars to the tooth surface. These structural changes are a result of the higher concentration of insoluble extracellular polysaccharides (Xiao \& Koo, 2010).

However, there is not much knowledge about the effect of the exposure of root dentin to sucrose when using a model that has a microbial complexity similar to that of the oral environment. Therefore, this study assessed the mineral content of root dentin of a controlled and simplified microcosm model that was exposed to sucrose.

\section{MATERIAL AND METHOD}

The experiment was carried out in triplicate and its laboratory phase lasted five days. Bovine root dentin specimens were prepared and then used to produce caries-like lesions using a microcosm biofilm model. To prepare the inoculum, the saliva of two volunteers was collected and added to an artificial medium. Then, $2 \mathrm{~mL}$ of inoculum were placed in the wells of a 24-welled plate. Each dentine block (fixed in an orthodontic wire hook) was perpendicularly immersed in a well. The cariogenic challenges occurred during the four subsequent days according to each experimental condition $(n=4)$ : Group C - no inoculum and no sucrose (control), Group OS saliva inoculum without sucrose treatment, Group $3 S$ three daily immersions of specimens in $20 \%$ sucrose, Group 6 S - six daily immersions of specimens in $20 \%$ sucrose, Group CS - specimens continuously immersed in $5 \%$ sucrose.

Collection and preparation of dentin specimens: Dentin specimens were obtained from bovine incisors that had been disinfected in $10 \%$ formalin solution for 10 days (Dominici et al., 2001). Two diamond disks, separated $6 \mathrm{~mm}$ apart by a spacer, were used to obtain slices of the root at the enamel-cementum junction. The slices were sectioned mesio-distally and dentin specimens were obtained from the buccal and lingual surfaces of the root. The slicing procedures were carried out under refrigeration, using distilled and deionized water, to avoid cracking at the root. The remaining dentin was planned on a turntable using polishing sandpaper discs in a decreasing granulation sequence (Lippert et al., 2015). Specimens were ground and polished to reach a final dimensions of $6 x$ $7 \times 1.21( \pm 0.25 \mathrm{~mm})$ and were kept refrigerated in a humid environment at $23^{\circ} \mathrm{C}$.
A Knoop microhardness device (ARS FM 9000/ FV ARS 9000 series, Future Tech Corp., Tokyo, Japan) was used at the center of the specimens to measure its initial surface hardness. Five indentations, $100 \mu \mathrm{m}$ apart from each other, were carried out with a $10 \mathrm{~g}$ load for 5 seconds. Specimens whose initial dentin hardness was $20 \%$ higher or lower than the initial mean hardness were discarded. The selected specimens were randomly assigned to the five groups at each experimental stage.

Preparation of the biofilm fixture device: The dentin specimens were placed in orthodontic wire clamps and attached to a hook fitted to the base of the wells of a 24welled polystyrene plate. The clamps were positioned so that the specimens were perpendicularly placed in the culture medium (Ccahuana-Vásquez \& Cury, 2010). The hook-clamp-dentin specimens set was autoclaved before use.

Selection of saliva donors: Two adult volunteers were selected as saliva donors. The inclusion criteria were: to be in good systemic health and to have a normally stimulated salivary flow. Volunteers were considered ineligible if they: had used antibiotics or drugs known to interfere with the salivary flow in the previous three months, used orthodontics appliances, had active caries, periodontal disease or were smokers.

Growth conditions and experimental protocol: The saliva donors were instructed to suspend their oral hygiene for twenty-four hours and eat nothing for two hours before the saliva collection. To prepare the inoculum, approximately $10 \mathrm{~mL}$ ( $5 \mathrm{~mL}$ from each donor) of stimulated saliva was collected. The saliva samples of the two donors were mixed and inoculated into 100 $\mathrm{mL}$ of an artificial medium that consisted of meat extract (Oxoid), yeast extract (Acumedia), Proteose Peptone (Difco), Pig Gastric Mucin type III (Sigma), Sodium Chloride, Calcium Chloride, Potassium Chloride, and $1.25 \mathrm{~mL} / \mathrm{L}$ of filtered, autoclaved $40 \%$ urea solution at pH 6.61(Sigma) (Pratten et al., 1998). Glucose (1\%) was added to this medium. After 18 hours in a $10 \% \mathrm{CO}_{2}$ incubator at $37{ }^{\circ} \mathrm{C}$, the solution's optical density was measured.

After confirming the turbidity, the suspension was agitated and $2 \mathrm{~mL}$ were placed in each well of a 24welled plate, each containing one dentin specimen. The 24-welled plates were maintained in a $37^{\circ} \mathrm{C}$ environment with $10 \% \mathrm{CO}_{2}$ for 6 hours so that the bacteria could adhere to the dentin surface. After this period of time, the dentin specimens were transferred to another 24welled plate containing only fresh artificial medium. 
The cariogenic challenge was carried out for four days (96 h) under aseptic conditions in one of the following fashions: continuous exposure of the dentin specimens to $5 \%$ sucrose solution (CS), exposure of the dentin specimens to $20 \%$ sucrose solution six times per day (6S) or three times per day (3S) for $1 \mathrm{~min}$ and subsequent rinsing three times with $0.9 \% \mathrm{NaCl}$. 0S remained in an inoculated artificial saliva medium with no sucrose exposure. C (control) had no saliva inoculum or sucrose exposure. At the end of each day, all the specimens were transferred to another 24-welled plate containing fresh artificial saliva medium, including CS group.

Collection of biofilm: On the fifth day, 12 hours after the last exposure to sucrose, the biofilm was collected. Specimens were transferred to Eppendorf tubes containing $1 \mathrm{~mL}$ of sterile $0.9 \%$ saline solution and agitated with an ultrasonic tip at one $7 \mathrm{~W}$ pulse for $30 \mathrm{~s}$ (Branson, Sonifier 50, Danbury, CT, USA). Specimens were carefully removed from the suspension and stored for measurement of the dentin surface hardness. Aliquots of suspension were used to determine the dry weight and polysaccharide content.

Determination of dry weight: Volumes of $300 \mu \mathrm{L}$ of the biofilm suspension were placed in new eppendorfs that had been previously weighed and labelled. They were centrifuged ( $5 \mathrm{~min}, 10000 \mathrm{~g}$ ), the supernatant was discarded and the precipitate was rinsed with distilled and deionized water. The precipitate was desiccated for $24 \mathrm{~h}$. After this period, the eppendorfs were weighed. The dry weight of the precipitate was calculated by subtracting the initial weight of the eppendorfs (Salli \& Ouwehand, 2015).

Determination of polysaccharides: A further 300 $\mu \mathrm{L}$ of the suspension of the biofilm in $0.9 \%$ saline solution was removed and agitated in a vortex. Afterwards, the eppendorfs were centrifuged ( $5 \mathrm{~min}$, $10000 \mathrm{~g})$, and the soluble extracellular polysaccharides (SEP) in the supernatant were measured. To the precipitate, $300 \mu \mathrm{L}$ of $1 \mathrm{M} \mathrm{NaOH}$ solution was added and agitated. The resulting suspension was centrifuged and the supernatant was used to quantify the insoluble extracellular polysaccharides (IEP). To the resulting precipitate of this stage, $300 \mu \mathrm{L}$ of $1 \mathrm{M} \mathrm{NaOH}$ solution was added and heated in a water bath $\left(100^{\circ} \mathrm{C}\right)$ for $15 \mathrm{~min}$. After centrifuging the suspension, the supernatant obtained was used for the quantification of the intracellular polysaccharides (IPS) (Cury et al., 2000). The polysaccharides analyses (SEP, IEP and IPS) were carried out using the phenol-sulphuric colorimetric method (DuBois et al., 1956) and read in a spectrophotometer(UV/VIS Ultrospec 1100 pro, Amersham Biosciences Corp., USA) at $480 \mathrm{~nm}$ absorbance. The results were normalized by the biofilm dry weight.

Analysis of the dentin demineralization: After the experiment, the surface hardness was measured again at a $100 \mathrm{~mm}$ distance from the baseline measurement site and described as the percentage of surface hardness loss (\% SHL), using the formula: (Initial Hardness - Post-treatment hardness) x 100/ Initial hardness. The SHL was used as an indicator of root dentin demineralization.

Statistical Analysis: The assumptions of equality of variances and normal distribution of errors were checked for all the response variables tested and the data that did not comply with the assumption were transformed when necessary (Box et al., 2005). The original SHL data were transformed to the power of 1.5 and the polysaccharides with base 10 logarithm. SAS software (version 9.0, SAS Institute Inc., Cary, NC, USA) was used for statistical analysis. ANOVA followed by Tukey test were used to compare the transformed variables and the significance level was $5 \%$.

Ethics: This study was carried out according to the rules of Resolution No. 466/2012 of the Brazil National Health Council, which regulates research in humans and Declaration of Helsinki. The Ethics Committee of the Federal University of Piauí approved this study under opinion 817177 . The volunteers who donated saliva signed an Informed Consent Form (ICF). The study had no risks, losses, injuries or forms of compensation and reimbursement of expenses.

\section{RESULTS}

SHL was greater in the group under continuous exposure to sucrose (CS), and there was a statistically significant difference $(p<0.001)$ among the other experimental groups (Table I).

The concentration of extracellular polysaccharides (soluble and insoluble) was greater in CS than in the other groups $(p<0.001)$. The other groups presented no statistically significant difference between each other ( $p>0.005)$ (Table II). 
Table I. Initial and final dentin surface hardness $(\mathrm{KHN})$ and its variation according to the experimental group.

\begin{tabular}{cccc}
\hline Treatment Groups & \multicolumn{2}{c}{ Surface Hardness } & \%SHL ${ }^{*}$ \\
& Initial & Final & \\
\hline C & $46.66 \pm 5.76$ & $38.81 \pm 4.18$ & $-16.10 \pm 10.37^{\text {A }}$ \\
OS & $48.86 \pm 4.49$ & $33.74 \pm 3.44$ & $-32.62 \pm 4.90 \mathrm{~B}$ \\
6S & $50.19 \pm 5.00$ & $21.87 \pm 2.72$ & $-55.94 \pm 7.58 \mathrm{C}$ \\
CS & $50.03 \pm 5.35$ & $16.19 \pm 2.61$ & $-67.18 \pm 6.90 \mathrm{D}$ \\
\hline
\end{tabular}

C - no inoculum and no sucrose (control); OS - saliva inoculum without sucrose treatment; $3 \mathrm{~S}$ - three daily immersions of specimens in $20 \%$ sucrose; 6 S - six daily immersions of specimens in $20 \%$ sucrose; CS - specimens continuously immersed in $5 \%$ sucrose. Different letters indicate a significant difference between treatment groups $(p<0.001)$. ${ }^{*}$ Surface hardness loss ${ }^{* *} n=11$, outlier removed.

Table II. Polysaccharide concentration (ug/mg dry weight) according to the treatments.

\begin{tabular}{cccc}
\hline Treatment Groups & \multicolumn{2}{c}{$\begin{array}{c}\text { Extracelular Polysaccharide } \\
\text { Soluble }\end{array}$} & $\begin{array}{c}\text { Intracellular Polysaccharide } \\
\text { Insoluble }\end{array}$ \\
\hline OS & $17.36 \pm 7.36 \mathrm{~A}$ & $30.74 \pm 11.70 \mathrm{~A}$ & $15.08 \pm 9.25^{\mathrm{A}}$ \\
3S & $18.30 \pm 10.47^{\mathrm{A}}$ & $37.10 \pm 24.94 \mathrm{~A}$ & $24.58 \pm 15.12 \mathrm{~A}$ \\
6S & $26.29 \pm 18.19^{\mathrm{A}}$ & $41.41 \pm 32.55 \mathrm{~A}$ & $27.35 \pm 13.93 \mathrm{~A}$ \\
CS & $78.54 \pm 49.26^{\mathrm{B}}$ & $98.73 \pm 82.31 \mathrm{~B}$ & $96.68 \pm 85.18 \mathrm{~B}$ \\
\hline
\end{tabular}

C - no inoculum and no sucrose (control); OS - saliva inoculum without sucrose treatment; $3 S$ - three daily immersions of specimens in $20 \%$ sucrose; 6 S - six daily immersions of specimens in $20 \%$ sucrose; CS -specimens continuously immersed in $5 \%$ sucrose. Different letters in the same column indicate statistically significant differences $(p<0.001)$.

\section{DISCUSSION}

Studies using an in vitro biofilm model are relevant strategies for evaluating caries and the changes caused in the substrate surface (Azevedo et al., 2011). Therefore, the biofilm and the substrate used should be as similar as possible to natural ones. Microcosm biofilm models use human saliva and simulate their microdiversity (Shu et al.; Filoche et al., 2007; Cenci et al., 2009). Therefore, this model was adopted in this study.

The SHL was greater when the biofilm microcosm model was continuously exposed to sucrose. These SHL results have been demonstrated in previous studies (Steiner-Oliveira et al., 2011; Cury et al., 2000), confirming that dental biofilm formed after exposure to sucrose has high cariogenic power. However, those studies used a different methodology, making it difficult to compare them with this study.

Dentin specimens of the groups that were exposed to sucrose (3S, 6S, CS) had greater mineral loss. The cariogenicity of the biofilm in a sucrosesupplied medium is due to the ability of the microorganisms to produce extracellular polysaccharides (EPS) and acids. EPS create a porous mesh, which acts as a support structure for the growth of microcolonies. Thus, the acids diffuse easily and reach the tooth-biofilm interface (Xiao \& Koo, 2010). Furthermore, the intracellular polysaccharides (IPS) maintain the low $\mathrm{pH}$ even during sucrose deprivation periods (Cury et al., 2000).

The constant presence of sucrose in the medium (CS), even in low concentrations, caused a greater change in the dentin surface when compared with that caused in $3 S$ and $6 \mathrm{~S}$. This result was expected because the permanent sucrose supply enables the natural selection of a less diverse, more acidic microbiota and therefore, the $\mathrm{pH}$ remains low (Aas et al., 2005; Rudney et al., 2012).

The greatest cariogenic potential of CS was corroborated by its highest values of polysaccharides when compared with the other groups (Table II). The higher polysaccharides production was probably due to the natural selection of Streptococcus mutans by this medium. The importance of bacteria in the etiology 
and pathogenesis of dental caries is due in part to the production of acid. However; the importance of the biofilm matrix cannot be over looked. The production of glucosyltransferases (GTFS) may increase the ability of $S$. mutans to compete with other oral species and allow the bacterium to persist at high levels on the surface for extended periods of time, leveraging the pathogenesis of dental caries (Koo et al., 2010). An insoluble matrix is formed for both the biofilm and other oral microorganism colonies (Bowen \& Koo, 2011).

Despite the fact that OS was not exposed to sucrose, there was visible biofilm accumulation and a significant SHL. This can be explained by the presence of meat extract, yeast extract, proteosepeptone and porcine gastric mucin in the artificial saliva medium (Pratten et al., 1998; Steiner-Oliveira et al., 2011), which might have been used as nutrients. Porcine gastric mucin is used as a substrate for saliva due to its similarities with the structure of oligosaccharides of human mucin saliva, which in turn, has been associated with the development of caries in the absence of other sources of nutrients (Kolenbrander, 2011).

One limitation of studies with biofilms is their reproducibility. A standard set of protocols should be adopted for these experiments (Yang et al., 2011). Another possible limitation of this study was the incubation protocol $(10 \% \mathrm{CO} 2$ instead of anaerobic environment), which could interfere with the microorganism diversity. Furthermore, additional studies are needed to identify the microorganisms of the model.

\section{CONCLUSION}

In conclusion, the microcosm biofilm model developed has the potential to produce root dentin demineralization at different exposures to sucrose. The mineral loss of dentin was modulated by the type of exposure of dentin to sucrose.

\section{ACKNOWLEDGMENTS}

The Laboratory of Postgraduate Dentistry Program of the Federal University of Ceará, Professor Monica Yamulti and, in particular, the technical manager David Queiroz.

BOHN, A. C. C. E.; VALE, G. C.; PADOVANI, G. C.;
RODRIGUES, L. K. A.; PRADO-JÚNIOR, R. R. Desmineralización de la dentina inducida por sacarosa en un modelo de biofilm microcosmo. Int. J. Odontostomat., 11(1):107-112, 2017.

RESUMEN: El objetivo de esta investigación in vitro fue evaluar la desmineralización de la dentina radicular causada por un modelo de biofilm microcosmo que fue expuesto de diferentes maneras a la sacarosa. La saliva de dos voluntarios fue colocada en un medio artificial para crecimiento del biofilm y los bloques de dentina fueron sumergidos en estos medios. Al aza rlos bloques fueron expuestos a una de las cinco condiciones experimentales: $\mathrm{C}$ (grupo control - sin inoculación de saliva o sacarosa), OS (inoculación de saliva sin sacarosa, control negativo), $3 S$ (tres inmersiones diarias de un minuto en sacarosa a 20 $\%$ ), $6 \mathrm{~S}$ (seis inmersiones diarias de un minuto en sacarosa a $20 \%$ ), y CS (sumergidos continuamente en $5 \%$ de sacarosa). Después de cinco días, el biofilm fue recogido para determinar la concentración de polisacáridos intracelulares y extracelulares y fue medida la pérdida de dureza superficial de la dentina (SHL). El experimento se repitió en tres ocasiones. La dentina SHL era mayor en los grupos que fueron expuestos a la sacarosa (3S, 6S E CS) y hubo diferencia estadísticamente significativa entre todos los grupos $(P<0,001)$. CS presentó mayor concentración de polisacáridos $(p<0,001)$ y no hubo diferencia estadísticamente significativa entre los demás grupos ( $0 S$, $3 S$ E 6S) ( $p>0,005)$. El modelo del biofilm desarrollado tiene potencial para producir desmineralización de la dentina radicular en diferentes exposiciones a la sacarosa.

PALABRAS CAVE: biofilm, dentina, sacarosa, polisacáridos.

\section{REFERENCES}

Aas, J. A.; Paster, B. J.; Stokes, L. N.; Olsen, I. \& Dewhirst, F. E. Defining the Normal Bacterial Flora of the Oral Cavity Defining the Normal Bacterial Flora of the Oral Cavity. J. Clin. Microbiol., 43(11):5721-32, 2005.

Aires, C. P.; Del Bel Cury, A. A.; Tenuta, L. M. A.; Klein, M. I.; Koo, H.; Duarte, S. et al. Effect of starch and sucrose on dental biofilm formation and on root dentine demineralization. Caries Res., 42(5):380-6, 2008.

Azevedo, M. S.; Van de Sande, F. H.; Romano, A. R. Cenci, M. S. Microcosm biofilms originating from children with different caries experience have similar cariogenicity under successive sucrose challenges. Caries Res., 45(6):510-17, 2011.

Bowen, W. H. \& Koo, H. Biology of Streptococcus mutans-derived glucosyltransferases: role in extracellular matrix formation of cariogenic biofilms. Caries Res., 45(1):69-86, 2011.

Box, G. E. P.; Hunter, J. S. \& Hunter, W. G. Statistics for Experimenters: Design, Innovation, and Discovery. 2nd ed. New York, John Wiley \& Sons, 2005.

Ccahuana-Vásquez, R. A. \& Cury, J. A. S. Mutans biofilm model to evaluate antimicrobial substances and enamel demineralization. Braz. Oral Res., 24(2):135-41, 2010. 
BOHN, A. C. C. E.; VALE, G. C.; PADOVANI, G. C.; RODRIGUES, L. K. A.; PRADO-JÚNIOR, R. R. Sucrose induced dentin demineralization in a microcosm biofilm model. Int. J. Odontostomat., 11(1):107-112, 2017.

Cenci, M. S.; Pereira-Cenci, T.; Cury, J. \& Tem-Cate, J. M. Relationship between gap size and dentine secondary caries formation assessed in a microcosm biofilm model. Caries Res., 43(2):97-102, 2009.

Cheng, L.; Exterkate, R. A. M.; Zhou, X.; Li, J. \& Ten-Cate, J. M. Effect of Galla chinensis on growth and metabolism of microcosm biofilms. Caries Res., 45(2):87-92, 2011.

Cury, J. A.; Rebelo, M. A. B.; Del Bel Cury, A. A.; Derbyshire, M. \& Tabchoury, C. Biochemical Composition and Cariogenicity of Dental Plaque Formed in the Presence of Sucrose or Glucose and Fructose. Caries Res., 34(6):491-7, 2000.

Dominici, J. T.; Eleazer, P. D.; Clark, S. J.; Staat, R. H. \& Scheetz, J. P. Disinfection/sterilization of extracted teeth for dental student use. J. Dent. Educ., 65(11):1278-80, 2001.

DuBois, M.; Gilles, K. A.; Hamilton, J. K.; Rebers, P. A. \& Smith, F. Colorimetric Method for Determination of Sugars and Related Substances. Anal. Chem., 28(3):350-6, 1956.

Filoche, S. K.; Soma, K. J.; Sissons, C. H. Caries-related plaque microcosm biofilms developed in microplates. Oral Microbiol. Immunol., 22(2):73-9, 2007.

Guggenheim, B.; Giertsen, E.; Schüpbach, P. \& Shapiro S. Validation of an in vitro biofilm model of supragingival plaque. J. Dent. Res., 80(1):363-70, 2001.

Kolenbrander, P. E. Multispecies communities: interspecies interactions influence growth on saliva as sole nutritional source. Int. J. Oral Sci., 3(2):49-54, 2011.

Koo, H.; Xiao, J.; Klein, M. I. \& Jeon, J. G. Exopolysaccharides produced by Streptococcus mutans glucosyltransferases modulate the establishment of microcolonies within multispecies biofilms. J. Bacteriol., 192(12):3024-32, 2010.

Lippert, F.; Churchley, D. \& Lynch, R. J. Effect of lesion baseline severity a nd mineral distribution on reminer alization and progression of human and bovine dentin caries lesions. Caries Res., 49(5):467-76, 2015.

Pratten, J.; Smith, A. W. \& Wilson, M. Response of single species biofilms and microcosm dental plaques to pulsing with chlorhexidine. J. Antimicrob. Chemother., 42(4):453-9, 1998.

Rudney, J. D.; Chen-Lenton, P.; Li, J.; Li, Y.; Jones, R. S. et al. A reproducible oral microcosm biofilm model for testing dental materials. J. Appl. Microbiol., 113(6):1540-53, 2012.

Salli, K. M. \& Ouwehand, A. C. The use of in vitro model systems to study dental biofilms associated with caries: a short review. J. Oral Microbiol., 7:26149, 2015

Shu, M.; Wong, L.; Miller, J. H. \& Sissons, C. H. Development of multi-species consortia biofilms of oral bacteria as an enamel and root caries model system. Arch. Oral Biol., 45(1):27-40, 2000

Silva, T. C.; Pereira, A. F. F.; Exterkate, R. A. M.; Bagnato, V. S.; Buzalaf, M. A. R.; Machado, M. A. et al. Application of an active attachment model as a high-throughput demineralization biofilm model. J. Dent., 40(1):41-7, 2012.

Steiner-Oliveira, C.; Rodrigues, L. K. A.; Zanin, I. C. J.; Carvalho, C. L.; Kamiya, R. U.; Hara, A. T. et al. An in vitro microbial model associated with sucrose to produce dentin caries lesions. Cent. Eur. J. Biol., 6:414-21, 2011.

Xiao, J. \& Koo, H. Structural organization and dynamics of exopolysaccharide matrix and microcolonies formation by Streptococcus mutans in biofilms. J. Appl. Microbiol., 108(6):2103-13, 2010.

Yang, L.; Liu, Y.; Wu, H.; Hóiby, N.; Molin, S. \& Song, Z. Current understanding of multi-species biofilms. Int. J. Oral Sci., 3(2):7481, 2011
Correspondence to:

Glauber Campos Vale

Dentistry Department

Federal University of Piauí

Campus Universitário Ministro Petrônio Portella

Teresina $(\mathrm{PI})$

BRAZIL

$\begin{aligned} & \text { Phone: } \text { +55 } 8632155888 \\ & \text { +55 } 86999129200\end{aligned}$

E-mail: valeglauber80@gmail.com

Received: 13-12-2016

Accepted: 30-12-2016 